\title{
A LEITURA LITERÁRIA COMO DIREITO HUMANO: EXPERIÊNCIAS DE LEITURA COMPARTILHADA EM BIBLIOTECAS COMUNITÁRIAS DO CIRANDAR
}

\section{LITERARY READING AS A HUMAN RIGHT: SHARED READING EXPERIENCES IN CIRANDAR'S COMMUNITY LIBRARIES}

\author{
Renata TOIGO* \\ Regina KOHLRAUSCH ${ }^{* *}$
}

\begin{abstract}
Resumo: No presente artigo, tendo como base a convicção de que a literatura é um direito humano básico, apresentamos, como exemplo de compromisso de formação leitora e de letramento literário, as ações realizadas nas bibliotecas comunitárias do Centro de Integração de Redes Sociais e Culturas Locais - Cirandar. A escolha desse modelo visa a divulgar e a incentivar uma prática comprometida com a formação do mediador de leitura e, principalmente, com a formação leitora, pois considera texto, contexto e intertexto para validar as culturas e saberes diversos. Para isso, Candido (1988 (2004)), Queirós (2009), Patte (2012), Petit (2013), Cosson (2011), entre outros estudiosos relacionados à formação e mediação leitora, são usados como referência e nos fazem entender, a partir das experiências em projetos de leitura do Cirandar, a importância dos espaços comunitários para a garantia do acesso à literatura.
\end{abstract}

Palavras-chave: Direitos Humanos. Biblioteca Comunitária. Leitura. Mediação. Formação Leitora.

Abstract: This paper is based on the belief that literature is a basic human right, and presents, as an example of commitment to reading training and literary literacy, the actions carried out in the community libraries of the Cirandar - Integration Center for Social Networks and Local Cultures. The choice of this model aims to disseminate and encourage a practice committed to the reading mediators' training and especially reader's training, considering text, context and intertextual reading and thus validating diverse cultures and cultural knowledge. For this, the concepts of Candido, Queirós, Patte, Petit, and Cosson were used as reference, among other scholars related to training and reading mediation.

Keywords: Human Rights. Community Library. Reading. Mediation. Reader Formation.

\section{Considerações iniciais}

O direito à leitura é um dos direitos fundamentais em uma democracia. O livro e a leitura são elementos que edificam uma nação, pois figuram entre as principais ferramentas que concorrem para a emancipação intelectual de seus cidadãos. Quanto mais letrado, mais condições um sujeito adquire de interpretar, questionar e reinventar sua realidade. Investir no acesso ao livro e à leitura é, portanto, investir na produção de autonomia para pensar, agir e

\footnotetext{
" Doutoranda em Letras da Pontifícia Universidade Católica do Rio Grande do Sul (PUCRS). E-mail: renata.toigo@acad.pucrs.br. ORCID: https://orcid.org/0000-0002-3158-3021.

** Professora titular da Pontifícia Universidade Católica do Rio Grande do Sul (PUCRS). Doutorado em Letras Teoria da Literatura pela PUCRS. E-mail: regina.kohlrausch@pucrs.br. ORCID: https://orcid.org/0000-00021410-7429.
} 
transformar o mundo. O livro literário contém uma capacidade revolucionária extraordinária. Logo, pensar o acesso ao livro, à leitura e à literatura, requer pensar em políticas públicas e democratização de acesso. Por conseguinte, criar bibliotecas comunitárias, como espaços de leitura, construídas nos seios de comunidades empobrecidas, a partir de seus desejos de evoluir, é um símbolo inexorável de resistência às políticas de austeridade que miram justamente nos territórios mais vulnerabilizados.

Ver a leitura como uma necessidade básica eleva a literatura como um direito humano essencial para todos, sem distinção de gênero, de etnia, de cultura ou de condição social. As políticas públicas de democratização de acesso à leitura, considerando as normativas e as leis, entre elas a lei $n^{\circ} .13696$ de 12 de julho de $2018^{1}$, divulgada no portal da Câmara dos Deputados e publicada originalmente no Diário Oficial da União, Seção 1, em 13/07/2018, página 1, que instituiu a Política Nacional de Leitura e Escrita “como estratégia permanente para promover o livro, a leitura, a escrita, a literatura e as bibliotecas de acesso ao público no Brasil"2, deveriam contemplar todos, sem distinção, mas sabemos que, na prática, no Brasil, isso ainda não é fato. Porém, algumas ações efetivas vêm buscando atenuar essa triste realidade, ao proporcionar espaços comprometidos com a formação leitora e com a formação do mediador de leitura, como é o caso das Bibliotecas Comunitárias, sobre as quais abordaremos neste artigo.

\section{O direito à literatura e a formação leitora nas Bibliotecas Comunitárias do Cirandar}

Antonio Candido (2004), no ensaio "O direito à literatura" 3 , atenta para os direitos humanos fundamentais que garantem a sobrevivência e a integridade social, como a alimentação, a moradia, o vestuário, a instrução, a saúde, a liberdade individual, o amparo da justiça pública, a resistência à opressão, também o direito à crença, à opinião, ao lazer e, por que não, interpela o estudioso, o direito à arte e à literatura? Para validar sua defesa a esse direito, Candido explica o que chama de literatura:

\footnotetext{
${ }^{1}$ Tramitação no Congresso Nacional como "Projeto de Lei do Senado $n^{\circ} 212$, de 2016, de autoria da Senadora Fátima Bezerra, que "Institui a Política Nacional de Leitura e Escrita". Disponível em: $<$ https://www.camara.leg.br/proposicoesWeb/prop mostrarintegra?codteor=1564983\&filename=PL+7752/2017 $>$. Acesso em: 27 abr. 2020, 18h30min.

${ }^{2}$ Política Nacional de Leitura e Escrita. Disponível em: <https://www2.camara.leg.br/legin/fed/lei/2018/lei13696-12-julho-2018-786975-publicacaooriginal-156036-pl.html>. Acesso em: 24 abr. 2020, 19h.

${ }^{3}$ Conforme levantamento, o texto tem sua origem como palestra proferida no curso organizado em 1988 pela Comissão de Justiça e Paz da Arquidiocese de São Paulo; publicado no ano seguinte em Direitos humanos e medo, organizado por Antonio Carlos Ribeiro Fester, São Paulo, Brasiliense, 1989; e recolhido posteriormente no volume Vários escritos. Neste artigo, a referência origina-se da obra $O$ direito à literatura e outros ensaios, com seleção e Posfácio de Abel Barros Baptista, publicado em Coimbra, pela editora Angelus Novus, em 2004, com Prefácio do próprio Candido.
} 
Chamarei de literatura, da maneira mais ampla possível, todas as criações de toque poético, ficcional ou dramático em todos os níveis de uma sociedade em todos os tipos de cultura, desde o que chamamos de folclore, lenda, chiste, até as formas mais complexas e difíceis da produção escrita das grandes civilizações (CANDIDO, 2004, p. 16).

Para ele, a literatura concebida nesse sentido amplo "parece corresponder a uma necessidade universal, que precisa ser satisfeita e cuja satisfação constitui um direito". (CANDIDO, 2004, p. 17). Assim, diz Candido, a literatura, alterando o conceito de Otto Ranke sobre mito é "o sonho acordado da civilização" (CANDIDO, 2004, p. 17). Dessa forma, conclui, como não há possibilidade de equilíbrio psíquico sem o sonho durante o sono, talvez não haja a possibilidade de equilíbrio social com a ausência da literatura. Por cumprir um papel de equilíbrio, a literatura é fator indispensável para a humanização do sujeito. É por isso que

\begin{abstract}
em nossas sociedades a literatura tem sido um instrumento poderoso de instrução e educação, entrando nos currículos, sendo proposta a cada um como equipamento intelectual e afetivo. Os valores que a sociedade preconiza, ou os que considera prejudicais, estão presentes nas diversas manifestações da ficção, da poesia e da ação dramática. A literatura confirma e nega, propõe e denuncia, apoia e combate, fornecendo a possibilidade de vivermos dialeticamente os problemas. Por isso é indispensável tanto a literatura sancionada quanto a literatura proscrita; a que os poderes sugerem e a que nasce dos movimentos de negação do estado de coisas predominantes (CANDIDO, 2004, p. 17).
\end{abstract}

Conforme Candido, a literatura não corrompe e nem edifica, mas, ao trazer em si aquilo que caracterizamos como o bem e aquilo de caracterizamos como o mal, segundo normativas sociais, ela humaniza porque faz viver, ou seja, porque faz vivenciar diferentes realidades e situações, porque satisfaz necessidades básicas e, sobretudo, enriquece a percepção e a visão de mundo do ser humano, sendo, por isso, uma necessidade universal imperiosa. Buscando deixar claro sua posição, Candido explica que entende humanização como

o processo que confirma no homem aqueles traços que reputamos essenciais, como o exercício da reflexão, a aquisição do saber, a boa disposição para com o próximo, o afinamento das emoções, a capacidade de penetrar nos problemas da vida, o senso da beleza, a percepção da complexidade do mundo e dos seres, o cultivo do humor. A literatura desenvolve em nós a quota de humanidade na medida em que nos torna mais compreensivos e abertos à natureza, à sociedade e ao semelhante (CANDIDO, 2004, p. 22).

O estudioso, ao mesmo tempo que mostra que a literatura humaniza e que "negar a fruição da literatura é mutilar a nossa humanidade", salienta que "a literatura pode ser um instrumento 
consciente de desmascaramento, pelo fato de focalizar as situações de restrição dos direitos, ou de negação deles, como a miséria, a servidão, a mutilação espiritual” (CANDIDO, 2004, p. 28). Assim, partindo desses dois níveis, Candido confirma que a literatura tem muito a ver com a luta pelos direitos humanos, defendendo que todos possam ter acesso aos diferentes níveis de cultura, porque "uma sociedade justa pressupõe o respeito dos direitos humanos, e a fruição da arte e da literatura em todas as modalidades e em todos os níveis é um direito inalienável” (CANDIDO, 2004, p. 33). Em outras palavras, uma sociedade que se quer de fato justa, presume o respeito e a luta pelos direitos humanos e o direito inalienável à arte e à literatura em todas as suas modalidades e em todos os níveis sociais.

Nessa mesma linha, seguindo a proposição de Candido, Bartolomeu Campos de Queirós, no "Manifesto por um Brasil literário", afirma que a literatura deveria ser um direito de todos, um direito que ainda não está legitimado, em comparação com outros direitos previstos em legislação. Para Queirós, é no mundo possível, criado pela ficção, que o ser humano pode pensar livremente e viajar por outro mundo, sem preconceitos, configurando alternativas e soluções “para as amarras da vida". É o que a literatura oferece: a criação, a imaginação, a recriação, o rompimento dos limites do provável, outras possibilidades, a transposição e reconfiguração de horizontes, preconiza o Manifesto ${ }^{5}$.

Levando em conta a defesa do direito à literatura proposta pelos dois humanistas, vem a pergunta sobre como garantir o acesso a bens culturais em uma sociedade que ainda não resolveu os problemas primordiais do "primo vivere" ${ }^{6}{ }^{6} \mathrm{Em}$ comunidades marcadas pela desigualdade social, como é o caso da sociedade brasileira, composta por pessoas que mal têm o que comer, resta fôlego para pensar em literatura e leitura?

É justamente nas comunidades mais empobrecidas que projetos de leitura alavancados por parcerias entre iniciativa privada e pública, destacando aqui as bibliotecas comunitárias, fazem toda a diferença no que diz respeito ao acesso ao livro, à leitura e à literatura. Nesses territórios, onde predominam a vulnerabilidade social, a precariedade das escolas, a violência doméstica, entre outros estigmas, a leitura da literatura, segundo Petit (2009), pode contribuir

\footnotetext{
${ }^{4}$ Esse manifesto, criado pelo escritor e poeta Bartolomeu Campos de Queirós, foi lançado durante a Festa Literária Internacional de Paraty - FLIP 2009 e ficou aberto para assinaturas no site <https://www.brasilliterario.org.br/>. O documento tem por objetivo debater ideias em torno da divulgação da literatura. Disponível em: <https://www.brasilliterario.org.br/manifesto/>. Acesso em: 24 abr. 2020, $18 \mathrm{~h}$.

${ }^{5}$ André Câmara, em Manifesto pelo direito a um país literário, também apresenta e explica a origem da criação do manifesto por um Brasil Literário, de Bartolomeu Campos de Queirós. Disponível em: <https://www.sesc.com.br/wps/wcm/connect/sesc/site/palavra . Acesso em 27 abr. 2020, 15h.

${ }^{6}$ Expressão de Sílvio Romero presente no texto A literatura e a sociedade no Brasil, no qual salienta que "o homem antes de ser um ente histórico é um indivíduo biológico, sendo sua principal preocupação o primo vivere" (ROMERO, 1978, p. 11).
} 
na reconstrução de si mesmo, já que é a literatura quem melhor expõe a experiência humana. Nesses espaços, considerados em crise, por reunirem uma série de ausências e marcadas, na maioria das vezes, por desavenças, a leitura é

\begin{abstract}
uma via privilegiada para recuperar a experiência da criança que, em um ambiente calmo, protetor, estético entre a sua mãe e ela, "trabalha" por meio do jogo da separação, se reestabelece, e se emancipa. E isso em todas as idades (...). As obras literárias esbanjam paisagens sem conta, incitando cada um a compor sua própria geografia. Contos, lendas, livros ilustrados, romances oferecem uma topografia, balizam o espaço, abrem-no para o exterior (PETIT, 2009, p. 93-94).
\end{abstract}

Mas o que são esses espaços de leitura chamados de bibliotecas comunitárias? No que diferem das demais bibliotecas? No Brasil, esse tipo de biblioteca, relativamente novo, criado por instituições não governamentais ou pela própria comunidade, buscando atender as demandas locais, surge de forma mais efetiva nas últimas décadas, frente a um processo histórico, social, cultural e político. No território brasileiro, intensificando e, de certa forma, unificando esse processo, foi criada, a partir de 2009, a Rede Nacional de Bibliotecas Comunitárias (RNBC), a qual define as bibliotecas como

\begin{abstract}
espaços de incentivo à leitura, que entrelaçam saberes da educação, cultura e sociedade, que surgem por iniciativa das comunidades e são gerenciados por elas; ou, ainda, espaços que, embora não tenham sido iniciativas das próprias comunidades, se voltam para atendê-las e as incluem nos processos de planejamento, gestão, monitoramento e avaliação. O que caracteriza as Bibliotecas Comunitárias é seu uso público e comunitário, tendo como princípio fundamental a participação de seu público nos processos de gestão compartilhada ${ }^{7}$.
\end{abstract}

Por sua natureza e origem, as bibliotecas comunitárias geralmente estão localizadas em periferias das grandes cidades, onde a atuação do Estado, na garantia de direitos básicos, é praticamente inexistente. Elas são fundadas e estabelecidas em contextos onde a leitura não é, a princípio, prioridade, pois as pessoas que ali moram fazem parte do conjunto humano esquecido e, por isso, econômico e socialmente excluído. Vale destacar que, apesar da exclusão e da indiferença, essas comunidades são espaços de muitos saberes culturais e populares, ambientes acolhedores e bonitos, naquilo que é a sua natureza, onde a vida em comunidade pulsa diariamente.

Na perspectiva dessas bibliotecas, a leitura, nesses territórios empobrecidos e esquecidos, é considerada como direito humano de todos e não apenas das camadas mais privilegiadas. Por isso, esses espaços são criados tendo como base o trabalho de formação de leitores e também

\footnotetext{
${ }^{7}$ Disponível em: 〈https://rnbc.org.br/>. Acesso em 20 abr. 2020, 15 h.
} 
de participação efetiva nas políticas públicas, com o objetivo de "ampliar o acesso da comunidade à informação, à leitura e ao livro, com vistas a sua emancipação social" (MACHADO, 2008, p. 64) e, assim, democratizar o acesso aos bens culturais.

Convém salientar que a permanência e manutenção das bibliotecas comunitárias depende de parcerias público-privadas, coincidindo com a tendência da contemporaneidade, uma vez que se evidencia que a sociedade, em geral, vem incorporando as práticas sociais como forma de responsabilidade social. É nesse contexto de comprometimento, que encontramos muitas associações, fundações, ONGs e Organizações da Sociedade Civil de Interesse Público (OSCIP) envolvidas em projetos direcionados às comunidades, que visam a integração e atuação da sociedade, em diferentes áreas, incluindo aí ações de formação de mediadores de leitura, formação de leitores e criação de espaços com o objetivo, ao mesmo tempo, de valorizar as culturas locais e garantir o direito à literatura.

Partindo dessa contextualização, no presente estudo, como já mencionado, nosso olhar volta-se para as ações de mediação de leitura desenvolvidas pelo Centro de Integração de Redes Sociais e Culturas Locais (Cirandar) ${ }^{8}$, gestor de bibliotecas localizadas em periferias do município de Porto Alegre. O Cirandar é uma organização sem fins lucrativos, que dialoga e repensa alternativas em vistas à educação, à transformação e à inclusão dos sujeitos culturais, comunicativos e criativos ${ }^{9}$.

Os programas e projetos de intervenção são pautados na educação popular como ferramenta de transformação social, e se propõem a apoiar, a incentivar e a criar redes de ações comunitárias e práticas sustentáveis, fomentando alianças de fortalecimento da cidadania. Para isso, o Cirandar desenvolve quatro linhas de atuação: (i) democratização do acesso ao livro e à literatura; (ii) formações, cursos e educação popular; (iii) fomento à arte e cultura; (iv) fortalecimento de redes e organizações. A primeira linha de ação contempla a convicção da instituição de que "a leitura é um direito humano essencial para a conscientização, a

\footnotetext{
${ }^{8}$ Criado em 2008, o Cirandar, ao longo de 11 anos de vida, formou e fortaleceu cerca de 15 bibliotecas comunitárias em Porto Alegre, criando o Redes de Leitura, a rede de bibliotecas é chamada hoje de Beabah. Atualmente a instituição gerencia três bibliotecas comunitárias: Biblioteca Comunitária Chocolatão, Biblioteca Comunitária do Arquipélago e Biblioteca Cirandar. Mais informações sobre o Cirandar estão disponíveis em: <https://www.cirandar.org.br/>. Acesso em: 20 abr. 2020, 16h.

9 A formação leitora nas bibliotecas comunitárias do Cirandar foi tema central da dissertação de mestrado de Renata Toigo, orientada pela professora $\mathrm{Dr}^{\mathrm{a}}$ Regina Kohlrausch. De modo que este texto traz alguns recortes de temas da pesquisa. Um estudo completo, sobre a formação leitora nas bibliotecas comunitárias do Cirandar, pode ser encontrado na dissertação. Disponível em: <http://tede2.pucrs.br/tede2/handle/tede/8460>. Acesso em: 03 maio 2020, $15 \mathrm{~h}$.
} 
curiosidade e o empoderamento das pessoas" ${ }^{10}$, estando, assim, em consonância com a posição de Candido, defendida em 1988, e de Queirós, conforme expresso no seu Manifesto de 2009. Por acreditar nesse direito, o Cirandar trabalha com o objetivo de criar, de apoiar e de potencializar ações e projetos relacionados à formação de leitores.

As bibliotecas comunitárias, neste caso, aquelas organizadas pelo Cirandar, são pequenos espaços, movidos pelo desejo de alcançar aqueles que estão à margem da sociedade, com base no conceito de "Small is beautiful"11, ou seja, "bastam um tapete e alguns cestos de livros escolhidos com cuidado. O essencial da biblioteca está aí” (PATTE, 2012, p. 103). Para Patte, esses pequenos espaços, chamados, no Brasil, de bibliotecas comunitárias, têm a consciência de uma

\begin{abstract}
falta que deve ser reparada. Elas têm o desejo de dividir um tesouro que não pode ficar reservado apenas para alguns. Elas sabem que a leitura, na medida em que abre caminhos, ajuda a lutar contra os determinismos e a lançar um olhar novo sobre a vida e os mundos próximos e distantes. A biblioteca é, portanto, necessária, lá onde a vida é particularmente difícil, às vezes mesmo alienante. É inútil esperar grandes recursos para começar. É preciso pôr mãos à obra sem demora e ir juntar-se às pessoas lá onde elas vivem, para que os livros se encontrem ao alcance das mãos, no coração da realidade de suas vidas. Essa proximidade é essencial (PATTE, 2012, p. 104).
\end{abstract}

As bibliotecas do Cirandar possuem a maior parte das características essenciais das bibliotecas contemporâneas: o espaço é convidativo, possuem livros escolhidos com cuidado, têm a presença de um mediador que lhes dá vida, e a liberdade oferecida às crianças permite que elas sintam a biblioteca como uma segunda casa, pois elos fortes se estabelecem nas cirandas da leitura.

Quando se fala das escolhas dos livros para a composição do acervo, o Cirandar, como instituição gestora e formadora, tem um olhar atento na seleção dos exemplares, escolhe colocar no caminho de cada leitor obras que dialoguem com as culturas e saberes locais. Essa preocupação do Cirandar está alinhada com o pensamento de Silvia Castrillón (2011) exposto no livro $O$ direito de ler e de escrever. Na obra, a estudiosa destaca que as bibliotecas devem ser planejadas juntamente com a comunidade e assim constituir um acervo que propicie a leitura como meio de inclusão e não como ferramenta de exclusão de leitores, por não se identificarem com os livros disponíveis no acervo. Ela afirma que precisamos de espaços de leitura que

\footnotetext{
${ }^{10}$ Conforme documento institucional. Disponível em: 〈https://www.cirandar.org.br/democratizacao $>$. Acesso em 20 abr. 2020, $14 \mathrm{~h}$.

${ }^{11}$ A expressão small is beautiful, foi utilizada aqui a partir da obra Deixe que leiam, de Geneviève Patte. Ela utiliza a expressão para descrever os espaços alternativos de biblioteca. Espaços que não estão preocupados com a quantidade de livros, mas sim com a qualidade do acervo e na afetividade de quem trabalha ali.
} 
promovam o gosto pela leitura e que também "permitam a descoberta do valor que ela tem como meio de busca de sentido, como referência de si mesmo no mundo e para o reconhecimento do outro" (CASTRILLÓN, 2011, p. 38).

É importante salientar que, por meio da leitura da literatura, segundo Petit (2009), a interioridade do ser humano se modifica, já que ela oportuniza ao leitor, que vive em espaços de crise, a possibilidade de recuperar e de estimular sua persistência existencial. No entanto, alerta a estudiosa, a leitura por si só

não é suficiente para fornecer tais representações e para restabelecer os que viveram dramas ou as inúmeras separações que são comuns da vida. São necessários vínculos sociais, amor, amizade, projetos divididos, às vezes outras práticas culturais (...) uma intersubjetividade com profissionais da escuta (PETIT, 2009, p. 115).

Ou seja, em territórios caracterizados por uma série de dissabores, não adianta termos somente o espaço físico, a biblioteca, bem como o suporte físico, o livro, é preciso mediar o caminho entre o real e o imaginário. Portanto, é necessária a presença e a escuta como ponto fundamental na prática de mediação de leituras. Esse papel de presença e escuta, nas bibliotecas comunitárias, é exercido geralmente por um mediador de leitura/educador social, que tem o papel de provocar no leitor o desejo de ler. O interesse despertado no leitor depende muito do entusiasmo e da apresentação que o mediador suscita nas leituras e das possibilidades que permite ao leitor explorar.

Por isso, as bibliotecas comunitárias gestadas pelo Cirandar, privilegiam sempre a abertura de suas portas para o universo da leitura, oferecendo às crianças a oportunidade de contato com os livros. As crianças podem entrar, escolher um livro e ali permanecer como se fosse uma segunda casa, ou melhor, como uma extensão de suas "próprias casas". O ambiente acolhedor estimula esse convívio e se, como ocorre muitas vezes, as crianças vão até a biblioteca somente para passear, em algum momento um livro despertará o interesse, o qual servirá como ponte entre o real e o fictício. Dessa forma, aos poucos, elas vão ali permanecendo para participar das rodas de leitura, das mediações e demais ações culturais promovidas pelos educadores sociais que têm um olhar atento e ouvido aberto para a escuta.

$\mathrm{Na}$ prática, nesses espaços alternativos, atentos ao seu propósito, se desenvolve uma leitura compartilhada, responsável por proporcionar vivências literárias: primeiramente ao mediador, pois ele precisa se tornar um leitor a fim de mediar leituras; depois, com as crianças que, ao ouvir essas histórias, são despertadas para a experiência da sensibilidade. Nesse sentido, nas bibliotecas comunitárias, as atividades de mediação de leitura, realizadas pelos educadores 
sociais, estão em sintonia com a proposição de Michèle Petit, quando ela explica que depende da escolha do texto feita, por um lado, pelos leitores e, por outro, pelos mediadores, que o trabalho se conforma, ao mesmo tempo, como promoção da leitura propriamente dita e / ou afirma-se como forma de incentivar e até melhorar e intensificar a autoestima do leitor.

Além de reiterar o papel humanizador da literatura, o Cirandar tem também a preocupação com a formação de um leitor crítico, que consiga estabelecer elos com sua cultura e com seu território. Para isso, as atividades de mediação de leitura, realizadas pelo Cirandar, são planejadas e elaboradas em três etapas: sensibilização, mediação e ação cultural. Essas etapas estão em consonância com a proposta de letramento literário de Rildo Cosson (2011), pensadas de forma linear, na seguinte sequência: antecipação, decifração e interpretação.

Para o estudioso, a antecipação consiste nas operações que o leitor vai realizar antes de adentrar no texto, considerando os elementos que compõem a materialidade da obra, como o título, a capa, quantidade de páginas, ilustrações, entre outros textos escritos ou visuais que auxiliam na sensibilização para a leitura. A segunda etapa, a decifração, é a leitura do texto em si, escrito e/ou ilustrado. A interpretação, terceira etapa, é a relação estabelecida pelo leitor ao processar o texto, ou seja, depende do que escreveu o escritor, do que leu o leitor, seu conhecimento de mundo, horizonte de expectativas e das convenções que regulam a leitura em uma determinada sociedade, ou seja, "interpretar é dialogar com o texto tendo como limite o contexto" (COSSON, 2011, p. 41). Para o estudioso, as práticas dos projetos de leitura precisam contemplar o processo de letramento literário, e não apenas a mera leitura das obras, pois:

ler é um processo que, qualquer que seja o ponto de partida teórico, passa necessariamente pelo leitor, autor, texto e contexto. Sem um deles, o circuito não se completa e o processo resulta falho. O diálogo da leitura implica ouvir o autor para entender o texto, construir o sentido do texto porque se compartilha os sentidos de uma sociedade; ou construir o sentido do texto ouvindo o autor e compartilhando os sentidos de uma sociedade no entendimento do texto (COSSON, 2017, p. 41).

Sobre os quatro elementos - leitor, autor, texto e contexto -, não importa qual seja usado como ponto de partida para a leitura, eles devem ser igualmente reconhecidos como partes do processo de construção de sentido. A concepção de leitura do pesquisador é que o leitor comece a leitura com uma indagação, pois "se a leitura é um diálogo, todo diálogo começa essencialmente com uma pergunta, $[. .$.$] , cuja resposta nos leva a outra pergunta e a outra$ resposta e a outra pergunta (COSSON, 2017, p. 41). Ler, segundo Cosson, é o resultado da vontade de conhecer. Lendo é que desenvolvemos nossa capacidade de leitura. 
Ler literatura orienta para indagações acerca de nossa identidade, quem somos, como queremos viver, trazendo a possibilidade de avaliação dos valores impostos socialmente, desafiando os discursos já prontos como verdades únicas e imutáveis, nos oferece a liberdade de modo que nenhuma outra maneira de ler oferece. E mais, o ato de ler, tomado como um diálogo, é mediado por três objetos de leitura literária: "texto, contexto e intertexto" (COSSON, 2017, p. 63). De acordo com os estudos de Cosson (2017), o texto, entendido como a unidade central, em se tratando da literatura infantil, associa o texto escrito ao texto visual, a ilustração; o contexto, concebido como espaço no qual a unidade está inserida, abrange áreas diversas como a história, a biologia, a filosofia, a linguística, a antropologia; e o intertexto, vai além do texto, aproxima diferentes textos e mostra como eles se relacionam entre si. Ou seja, o ato de ler constitui-se "em um processo envolvendo autor, leitor, texto e contexto em uma relação de diálogo que tem como objetos o texto, o contexto e o intertexto" (COSSON, 2017, p. 63). Logo, conforme a tese do estudioso, é do diálogo, entre elementos e objetos, que surgem as diferentes maneiras da leitura literária. Esses diversos modos de ler nos demonstram que a leitura literária não tem apenas uma trilha a ser seguida e o diálogo da leitura pode ser iniciado de diversas maneiras, bem como pode ser realizado através de diferentes atividades.

As três etapas de leitura, que guiam a proposta de letramento literário de Cosson, equivalem à metodologia adotada pelo Cirandar. Na primeira etapa, chamada de sensibilização, que é quando se busca garantir a atenção dos ouvintes para a expressão cultural que vai ser vivenciada, consiste nas operações realizadas antes de adentrar no texto. É o momento em que o educador social utiliza estratégias de conquista do silêncio do grupo, falando com calma e atenção, convida as crianças para sentar em roda. Para essa roda, são oferecidas atividades como: cantigas, utilização de instrumentos musicais, poemas, parlendas, charadas, falas sobre autor, capa do livro ou tema da história a ser mediada. Enfim, atividades de curta duração para despertar o interesse para a história em questão.

Na mediação, segunda etapa, o foco está na leitura da obra em si, escrita e/ou ilustrada, com vistas ao encantamento pela leitura. As estratégias utilizadas pelo mediador, que buscam despertar esse prazer, destacam-se: domínio do texto a ser lido; tom de voz adequado; ênfase nas principais partes da história; estudo antecipado das palavras e expressões desconhecidas. Para isso, ou seja, para alcançar o encantamento, o mediador pode usar as diversas maneiras de leitura, entre elas: a leitura do texto mostrando as imagens momentaneamente; a leitura do texto sem mostrar as imagens; a leitura do texto e o convite aos leitores para participarem de repetições; a leitura do texto fazendo as vozes dos personagens; o convite a um leitor para que 
leia o texto; a leitura de algumas partes e outras contadas ou a contação da história com as próprias palavras, tendo o texto escrito como apoio. Além dessas maneiras de leitura, tem grande importância também o modo de ouvir as histórias: pode ser organizados em roda, sentados em cadeiras, almofadas, ou direto no tapete; pode ser de olhos vendados, sentados ou deitados; se a história for de suspense, pode-se deixar o ambiente escuro, entre outras possibilidades, sempre a critério do mediador, conforme capacitação oferecida pelo próprio Cirandar, uma vez que sua preocupação também se volta à formação dos mediadores de leitura ou dos educadores sociais.

$\mathrm{Na}$ ação cultural, terceira etapa, é o momento de ler nas entrelinhas e de ler em diálogo com as outras linguagens artísticas. Também aqui são utilizadas estratégias para pensar, a partir do texto, o contexto em que o público está inserido, sempre levando em conta que diferentes histórias oferecem uma diversidade de possibilidades de ações culturais. Partindo dessas estratégias, são realizadas ações que dialogam com o texto mediado e/ou com o contexto em que a comunidade está inserida, a saber: construir um outro final para a história, recontar a história, ilustrar a partir de um tema, conversar sobre o tema do texto, criar brincadeiras que tenham relações com a história, realizar uma caminhada na comunidade, conversar e debater sobre temas e assuntos que os textos suscitam, confeccionar algum objeto de maneira individual ou coletiva, entre tantas outras possibilidades ${ }^{12}$.

Salientamos que esses momentos de leitura compartilhada, vivenciados nas bibliotecas do Cirandar, não são desprovidos de sentido, estão conectados com os aspectos culturais das comunidades atendidas, logo, estão também de acordo com os pressupostos de Cosson (2017), do diálogo entre texto, contexto e intertexto. Essa forma de atuação permite criar vínculos sociais de amor e amizade com as crianças, jovens e adultos que ali chegam, sendo a presença e a escuta fundamentais, já que a leitura por si só é insuficiente para restabelecer os dramas existenciais e as separações habituais da vida, reiterando o que foi salientado por Petit (2009). Essa intersubjetividade com os profissionais da escuta, dialogando com as culturas locais e outras práticas, se faz necessária para formar sujeitos de voz ativa na luta por seus direitos, ou seja, confirma o objetivo de formar sujeitos críticos tendo como base e suporte a leitura da literatura.

Ao utilizar o livro como protagonista, isto é, como principal elemento na mediação, o Cirandar acredita estar dando ao texto literário seu merecido valor, porque considera que a palavra literária tem poder desafiante, pois confronta nossas certezas com o universo ficcional.

${ }^{12}$ Dados retirados de material de formação para mediadores de leitura nos arquivos do Cirandar.

Revista Graphos, vol. 22, n² 2, 2020 | UFPB/PPGL | ISSN 1516-1536 
Nessa perspectiva de atuação do Cirandar, o livro, como veículo das narrativas ficcionais ou da expressão poética, é necessário e fundamental. Aos poucos e ao ser disponibilizado nas bibliotecas comunitárias, ele passará a fazer parte da vida daqueles que o escolhem, a ponto de (e é essa a motivação central) os indivíduos não conseguirem passar seu dia a dia sem a palavra literária, conformando-se, assim, o leitor. Portanto, para a solidificação dessa postura leitora, é preciso despertar o prazer para a leitura da palavra literária, para, depois, conectá-la com outras linguagens, como se propõe na terceira etapa, ou seja, estabelecer as relações do texto lido e comentado com o contexto interno e externo que envolve a comunidade, incluindo as demais linguagens artísticas.

Cabe destacar que essa proposição, apresentada pelo Cirandar como fundamento para o fortalecimento das bibliotecas comunitárias em Porto Alegre/RS, entidade escolhida como modelo para este artigo, está relacionada com a convicção de que, nesses cenários periféricos, onde estão localizados esses espaços de leitura, em que à distância geográfica das regiões centrais, somam-se a fragilidade, as dificuldades econômicas, os obstáculos psicológicos e sociais, a alta criminalidade, o tráfico de drogas e o abandono familiar, entra o livro, como objeto raro, pouco familiar, investido de poder, que está separado por fronteiras visíveis ou invisíveis, explica Petit. Como diz a estudiosa, "se os livros não vão até eles, eles nunca irão até os livros" (PETIT, 2013, p. 24). É nessa fronteira que, além do livro, entra também o educador social, que transcende o espaço da biblioteca e percorre a comunidade, pega os leitores pelas mãos e convida a entrar no universo da leitura e no espaço da biblioteca comunitária. Nesse sentido, a biblioteca comunitária configura-se como uma instituição social que abre suas portas para outras possibilidades, oportunidades para o mundo da fantasia e do afeto.

Frente a isso, romper fronteiras e oferecer o livro juntamente com afeto, as atividades planejadas para as medições de leitura realizadas nas bibliotecas do Cirandar visam contribuir para a formação leitora. Para isso, elas voltam-se à emancipação do leitor, com vistas a oportunizar a passagem de leitor iniciante para leitor em formação até chegar ao que denominamos de leitor autônomo, que é aquele que entra na biblioteca e já sabe estabelecer preferências entre um escritor ou outro, ou entre gêneros literários e levar o livro para leitura em casa.

\section{Considerações finais}

Reiteramos, portanto, que é importante convencer-se e convencer ao outro de que nas comunidades e territórios afetados por uma série de desequilíbrios e dissabores é também o 
lugar por onde cirandam muitos saberes culturais e populares. A presença de bibliotecas comunitárias com programações culturais conectadas com experiências compartilhadas, onde mediador e leitor constituem fortes vínculos em torno da leitura da literatura é um significativo potencial na reconstrução ou reconfiguração desses sujeitos. É, pois, nesses espaços alternativos, uma vez que o estado institucional não está, de fato, presente, que a leitura da literatura cumpre com mais de uma função: a de formar leitores críticos, com poder de voz em seus espaços sociais e políticos, a partir das mediações de leitura sistematizadas em uma proposta de letramento literário, bem como, possibilitar a emancipação dos sujeitos deixados à margem pela sociedade. Em outras palavras, a leitura consegue ser essa linha de fuga ou de evasão desse confim, porque, como afirma Petit (2009), é a leitura da literatura que permite "atravessar a noite, enfrentar a escuridão e a separação" (p. 65). Dessa forma, as experiências vivenciadas nas bibliotecas aqui mencionadas corroboram com a tese de Petit (2009), de que a leitura da literatura é um meio de resistência às adversidades próprias dos tempos difíceis e em espaços em crise, ao mesmo tempo em que colocam em prática a inclusão da literatura como direito humano defendido por Candido e Queirós.

Vale destacar o importante trabalho realizado pelas diferentes Organizações da Sociedade Civil, com projetos desenvolvidos para potencializar o terceiro setor, voltado, aqui neste texto, às bibliotecas comunitárias do Cirandar. Uma experiência real no campo da leitura, que mostra o que, como, onde e quando é possível fazer toda a diferença. Uma atuação no campo das políticas públicas, protagonizada por forças não governamentais que se soma a outras lutas voltadas a esse campo. Em um país como o Brasil, com dimensões continentais, disparidades sociais, diversidade cultural, ações de leitura, desenvolvidas em espaços periféricos das grandes cidades, são de fundamental importância para a mudança da situação de exclusão do universo literário. Com onze anos de lutas dedicados a projetos sociais conectados com escolas e serviços locais parceiros, o Cirandar investe na democratização do acesso ao livro, à leitura e à literatura, garantindo um direito humano essencial para a conscientização, a curiosidade e o empoderamento das pessoas, por isso, trabalha com o objetivo de criar, apoiar e potencializar ações e projetos relacionados à formação de leitores.

Convém, por fim, insistir na importância do mediador de leitura uma vez que, quando não se dispõe da sorte de ter e ler livros em casa, de ver os próprios pais e demais familiares lendo, de poder escutá-los a contar histórias, as coisas podem mudar a partir de um encontro na biblioteca com o leitor mediador. Pois, como reitera Petit (2013), um mediador que valoriza e ama os livros vai passar para os seus ouvintes de histórias o mesmo sentimento, vai dar a mesma 
oportunidade de se relacionar com os livros e de manipulá-los, e vai encontrar palavras para legitimar a leitura. Logo, é preciso multiplicar as possibilidades de mediação, é preciso abrir as portas da biblioteca e convidar as crianças para entrar no mundo da leitura. Patte (2012) e Petit (2013) propagam que é preciso criar o tempo e abrir espaços onde o desejo de ler possa traçar seu caminho, muitas vezes lento, mas promissor.

Sabemos que ler literatura não transforma o mundo. No entanto, acreditamos que tal prática, a leitura da literatura, promovida e conectada com as culturas locais, pode ajudar a fortalecer os sujeitos sociais. Quando o homem vive sem contato com a linguagem, com a educação, com as relações humanas e com a arte, não concretiza sua capacidade nata de imaginar, sonhar, inventar, criar, inovar e construir.

Assim, defendemos, juntamente com as referências humanistas aqui citadas e o exemplo institucional do Cirandar aqui destacado, que ler literatura forma e transforma o ser humano, e, ao ser transformado, passa a ser ou pode ser agente de transformação da comunidade em que vive. Pois, afinal, já consenso entre os estudiosos, ninguém chega ao fim da leitura de um texto literário da mesma maneira que nele ingressou. Podemos sair mais alegres, mais tristes, mais esperançosos, mais confiantes, mais determinados, mais revoltados, mas nunca iguais, já que, como leitores, estamos aptos a discernir atitudes que exaltamos ou que recriminamos. Ressaltamos, portanto, seguindo Candido, que o direito à leitura e à literatura é essencial porque desenvolve em cada um de nós, leitores e leitoras, a quota de humanidade na medida em que nos torna mais compreensivos e abertos para a natureza, a sociedade e o semelhante.

\section{Referências}

CANDIDO, Antonio. O direito à literatura. In: BAPTISTA, Abel Barros (Org.). O direito à literatura e outros ensaios. São Paulo: Angelus Novus, 2004.

CASTRILlÓN, Silvia. O direito de ler e escrever. Tradução de Marcos Bagno. São Paulo: Editora Pulo do Gato, 2011.

COSSON, Rildo. Letramento literário: teoria e prática. São Paulo: Contexto, 2011.

COSSON, Rildo. Círculos de leitura e letramento literário. São Paulo: Contexto, 2017.

MACHADO, Elisa Campos. Bibliotecas comunitárias como prática social no Brasil. 2008. 184 f. Tese - Universidade de São Paulo, São Paulo. 2008. Disponível em: <https://www.teses.usp.br/teses/disponiveis/27/27151/tde-07012009-

172507/publico/Tese.pdf $>$. Acesso em: 25 set. 2020. 
QUEIRÓS, Bartolomeu Campos de. Movimento por um Brasil literário: manifesto.

Disponível em: 〈http://www.brasilliterario.org.br/manifesto/o-manifesto/>. Acesso em: 19 maio 2018.

PATTE, Geneviève. Deixem que leiam. Tradução de Leny Werneck. Rio de Janeiro: Rocco, 2012.

PETIT, Michèle. A arte de ler ou como resistir à adversidade. Tradução de Arthur Bueno e Camila Boldrini. São Paulo: Editora 34, 2009.

PETIT, Michèle. Leituras: do espaço íntimo ao espaço público. Tradução de Celina Olga de Souza. São Paulo: Editora 34, 2013.

ROMERO, Sílvio. A literatura e a sociedade no Brasil. In: CANDIDO, Antonio (Org.) Sílvio Romero: teoria, crítica e história literária. Rio de Janeiro: LTC, 1978, p. 11-24.

TOIGO, Renata. Desafios da formação leitora em bibliotecas comunitárias: registro, arquivo e memória de leitura da literatura infantil. 2019. 122 f. Dissertação - Pontifícia Universidade Católica do Rio Grande do Sul, Porto Alegre. 2019. Disponível em: <http://tede2.pucrs.br/tede2/handle/tede/8460>. Acesso em: 30 abr. 2020.

Recebido em: 03/05/2020 Aceito para publicação em: 02/09/2020 